\title{
PENGARUH METODE PENGGERUSAN TABLET VITAMIN C TERHADAP KADAR BAHAN AKTIF
}

\author{
Damaranie Dipahayu $^{* 1}$, Silfiana Nissa Permatasari ${ }^{1}$ \\ ${ }^{1}$ DIII Farmasi, Akademi Farmasi Surabaya \\ *email: d.dipahayu@ akfarsurabaya.ac.id
}

Received 3 September 2019

Accepted 31 December 2019

\begin{abstract}
Abstrak
Salah satu bentuk pelayanan resep adalah meracik sediaan serbuk (pulveres). Sediaan serbuk umumnya didapat dari teknik menggerus beberapa sediaan tablet dan mencampurnya. Teknik menggerus yang lazim dilakukan di apotek adalah secara manual dengan alat mortir-stamper dan menggunakan blender (alat pulverization). Penggunaan blender dirasa lebih praktis dan mempersingkat waktu namun demikian dikawatirkan panas yang ditimbulkan dapat menurunkan kadar bahan aktif yang tidak stabil terhadap adanya panas. Penelitian ini bertujuan untuk mengetahui apakah metode penggerusan manual dan blender terhadap tablet vitamin $\mathrm{C}$ akan mempengaruhi kadar asam askorbat. Metode yang dipakai pada penelitian ini adalah HPLC. Kadar asam askorbat serbuk vitamin C hasil gerus manual adalah 192,396 mg (18,807 $\pm 0,797 \%)$, sedangkan serbuk vitamin $\mathrm{C}$ hasil blender adalah $180,545 \mathrm{mg}(17,688 \pm 0,509 \%)$. Kesimpulan dari penelitian ini menunjukkan bahwa metode penggerusan secara blender dapat mengakibatkan penurunan kadar asam askorbat lebih besar dibanding dengan metode manual namun demikian kedua metode tersebut tetap dapat menjaga ketersediaan kandungan asam askorbat pada rentang konsentrasi $90 \%$ $110,0 \%$.
\end{abstract}

Kata kunci: tablet vitamin C, penggerusan, manual, blender, kadar asam askorbat, HPLC

\begin{abstract}
One of prescription services is preparing pulveres dosage form. Pulveres are obtained trough the crushing technique of several tablet and mixing them. The common crushing technique are manual using a mortar-stamper and automatic using a blender (pulverization machine). A blender technique is considered because it is more practice and shortens the time however the heat of blender can reduce an active ingredients levels which is unstable to high temperature. This study aims is to determine whether the manual crushing method and blender of vitamin $\mathrm{C}$ tablets will affect the levels of ascorbic acid as an active ingredients. This research uses HPLC method. The concentration of ascorbic acid of vitamin C that was crushed manually is $192,396 \mathrm{mg}(18,807 \pm 0,797 \%)$, while the blended vitamin C is 180,545 $\mathrm{mg}(17,688 \pm 0,509 \%)$. The conclusion of this study shows that the blender method can cause a decrease in ascorbic acid levels greater than the manual method however both methods can still maintain the availability of ascorbic acid content in the concentration range of $90 \%-110.0 \%$.
\end{abstract}

Keywords: Vitamin C tablet, crushing, manual, blender, ascorbic acid content, HPLC

\section{Pendahuluan}

Pelayanan kefarmasian di apotek salah satunya adalah peracikan sediaan pulveres yang umumnya dinamakan sediaan puyer
(Widyasari \& Wiedyaningsih, 2012). Sediaan puyer dipersiapkan melalui tahapan menggerus (memperkecil ukuran 
partikel), mencampur dan membagi. Bahan obat yang digerus biasanya dari bentuk kapsul dan tablet (Hasanah, 2003). Sediaan puyer memiliki efek terapi yang lebih cepat dibanding sediaan tablet karena memiliki luas permukaan lebih luas dan tidak melewati fase terdisintegrasi sehingga langsung dapat terdisolusi untuk kemudian terabsorbsi ( Allen \& Ansel, 2014).

Pelayanan peracikan sediaan puyer di apotek yang banyak dilakukan adalah secara manual menggunakan mortirstamper dan dengan cara menggunakan alat milling yaitu ball mill, grinder ataupun blender. Pemilihan metode penggerusan tergantung karakteristik bahan aktif (Bestari, Sulaiman \& Purnamasari, 2017). Penggerusan adalah proses mekanik untuk memperkecil ukuran zat padat. Istilah penggerusan dinamakan lain yaitu penghancuran, disintegrasi, disperse, penggilingan dan penyerbukkan. Penggerusan dilakukan dengan alat khusus, setiap alat memiliki proses tertentu (Lachman et al, 1989).

Apotek dengan jumlah pasien yang banyak, umumnya memilih cara penggerusan tablet dengan metode blender agar lebih cepat tanpa mempertimbangkan karakteristik bahan aktif (stabil atau tidaknya terhadap panas). Alat blender merupakan alat elektronik yang akan menghasilkan panas. Untuk mengetahui apakah proses penggerusan manual mortirstamper dibanding dengan alat elektronik ( alat pulverization) akan mempengaruhi kadar bahan aktif, maka diperlukan suatu penelitian tersendiri.

Berdasarkan latar belakang tersebut maka dilakukan penelitian uji kadar sampel serbuk vitamin $\mathrm{C}$ yang didapat dari tablet vitamin $\mathrm{C}$ yang digerus dengan alat manual dengan mortir- stamper dan dengan alat blender. Karakteristik vitamin $\mathrm{C}$ adalah sangat mudah teroksidasi oleh panas, cahaya dan logam. Vitamin $\mathrm{C}$ mudah larut dalam air. Bila suatu senyawa telah teroksidasi maka senyawa kimia tersebut tidak dapat lagi memiliki efektifitas sebagai antioksidan (Martindale $\mathrm{Ed}^{36}$, 2009). Vitamin $\mathrm{C}$ tidak stabil terhadap adanya panas dan menyebabkan kadar vitamn $\mathrm{C}$ dapat berkurang. Vitamin $\mathrm{C}$ juga sering diresepkan dokter dalam bentuk sediaan pulveres (serbuk). Vitamin $\mathrm{C}$ diperlukan untuk menjaga kesehatan dan perbaikan tulang rawan, tulang, dan gigi (Duerbeck et al., 2016). Vitamin C juga berfungsi sebagai antiskorbut (Gunawan et al 2018). Syarat kandungan asam askorbat sampel vitamin $\mathrm{C}$ pada penelitian ini mengacu pada persyaratan Farmakope Indonesia Edisi ke IV dimana tablet vitamin $\mathrm{C}$ mengandung asam askorbat tidak kurang dari $90 \%$ dan tidak lebih dari 110,0\% (Departemen Kesehatan RI, 1995).

Terdapat beberapa metode uji penetapan kadar vitamin $\mathrm{C}$ yaitu metode tritasi, metode spektrofotometri, metode titrasi iodium, metode DPPH dan metode HPLC (Techinamuti \& Pratiwi,2018) Metode HPLC memiliki sensitivitas lebih tinggi dibanding dengan menggunakan alat spektrofotometer UV-Vis. ( Jubahar, et al., 2015). HPLC merupakan metode yang tidak dekstruktif dan dapat digunakan baik untuk analisis kualitatif maupun kuantitatif serta memiliki kecepatan analisis dan kepekaan yang tinggi. (Gandjar \& Rohman, 2007). Menurut Munson, 1991 dalam Jubahar, et al., 2015 bahwa analisa kadar dengan HPLC ideal untuk beragam bahan aktif obat baik dalam sediaan maupun cairan biologis selain itu relatif sederhana dalam segi pengerjaannya namun memiliki kepekaan tinggi. Metode penetapan kadar vitamin $\mathrm{C}$ pada penelitian ini menggunakan metode HPLC.

\section{Metode Penelitian \\ Bahan Kimia}

Bahan atau Reagen kimia yang digunakan penelitian ini antara lain tablet vitamin C IPI, $\mathrm{KH}_{2} \mathrm{PO}_{4}$, metanol.

\section{Preparasi Pembuatan Serbuk Vitamin C \\ Tablet vitamin $C$ secara terpisah digerus} digerus dengan menggunakan mortir - 
stamper dan alat pulverization dan diayak dengan ayakan mesh 100 .

\section{Preparasi sampel vitamin $C$}

Serbuk vitamin $\mathrm{C}$ hasil penggerusan tablet vitamin $\mathrm{C}$ secara manual mortirstamper ( SVCM ) dan serbuk vitamin C hasil penggerusan tablet vitamin $\mathrm{C}$ dengan alat pulverization (SVCP), masing-masing ditimbang sebanyak 1,0 gram dan dilarutkan dengan metanol ad 50,0 mL.

Masing- masing sampel selanjutnya difilter dengan membran nylon 0,2 mikron dan dimasukan dalam vial analit

\section{Analisa Kuantitatif Dengan HPLC \\ Kondisi HPLC :}

Instrument : HPLC Agilent 1100 Series dengan autosampler dan detektor PDA

Kolom : Merck LiChrospher 100 RP-18, 4 x $250 \mathrm{~mm}, 5 \mu \mathrm{m}$

Laju Alir $\quad: 0,6 \mathrm{ml} /$ menit

Suhu $\quad: 22{ }^{\circ} \mathrm{C}$

$\lambda \quad: 260 \mathrm{~nm}$ untuk vitamin $\mathrm{C}$ dan

210 untuk asam tartarat (baku internal)

loop injeksi : $10 \mu \mathrm{L}$

\section{Pembuatan Fase Gerak}

Fase gerak yang digunakan adalah $\mathrm{KH}_{2} \mathrm{PO}_{4}$ 0,02 $\mathrm{M}$ dan metanol. Dimana perbandingan fase gerak $\mathrm{KH}_{2} \mathrm{PO}_{4} 0,02 \mathrm{M}$ dan metanol adalah 40:60 (v/v). $\mathrm{KH}_{2} \mathrm{PO}_{4}$ $0,02 \mathrm{M}$ dibuat dengan cara menimbang $\mathrm{KH}_{2} \mathrm{PO}_{4}$ sebesar $272 \mathrm{mg}$ dan dilarutkan dengan aquabidest pro injeksi dalam labu ukur sampai 100,0 mL kemudian disaring (Kumar, et al., 2011 dalam Jubahar, et al., 2015).

\section{Persiapan larutan baku induk Vitamin C}

Baku vitamin $C$ dibuat sebesar 1000 ppm dengan cara melarutkan 25,0 mg dalam 25,0 $\mathrm{mL}$ metanol (Departemen esehatan RI, 2009).

\section{Pembuatan Kurva Kalibrasi}

Larutan baku induk Votamin C 1000 ppm dipipet ke dalam labu ukur $10,0 \mathrm{~mL}$ masing- masing sebesar 5,0 mL; 4,0 mL;
3,0 mL; 2,0 mL dan 1,0 mL (500 ppm; 400 ppm; 300 ppm; 200 ppm dan 100 ppm), selanjutnya masing- masing disaring dengan membran nylon 0,2 mikron lalu diinjeksikan sehingga didapatkan luas area. Luas area vs kadar selanjutnya diplot menjadi persamaan regresi linier: $\mathrm{y}=\mathrm{a}+$ bx dan nilai korelasinya (Kumar, et al., 2011 dalam Jubahar, et al., 2015).

\section{Penentuan Kadar Vitamin C Dalam Sampel}

Serbuk sampel ditimbang masingmasing $1000 \mathrm{mg}$ dan dilarutkan dengan metanol p.a kemudian disaring dengan kertas saring dan ditampung pada labu ukur hingga 50,0 $\mathrm{mL}$ dan ditambahkan metanol p.a ad tanda. Larutan sampel disaring terlebih dahulu dengan membran nylon 0,2 mikron dan dimasukkan ke dalam vial analit kemudian diinjeksikan pada HPLC dengan fase gerak $\mathrm{KH}_{2} \mathrm{PO}_{4}$ 0,02 M dan metanol adalah 40:60 (v/v) (Kumar, et al., 2011 dalam Jubahar, et al., 2015).

\section{Analisis Data \\ Konsentrasi larutan sampel dihitung berdasarkan kurva kalibrasi larutan standar. Kadar vitamin C larutan sampel dihitung dengan persamaan regresi: \\ Dengan

$$
y=a+b x
$$ \\ a $\quad=$ Tetapan regresi (intersep) \\ $\mathrm{b} \quad=$ Koefisien regresi (slope) \\ $\mathrm{y}=$ Luas area \\ $\mathrm{x} \quad=$ Konsentrasi}

Rumus perhitungan untuk kadar vitamin C pada sampel adalah :

$$
\mathrm{C}=\text { Cs. Fp. V }
$$

Keterangan :

$$
\begin{array}{ll}
\mathrm{C} & =\text { Konsentrasi sampel } \\
\mathrm{Cs} & =\text { Konsentrasi yang diperoleh dari } \\
& \begin{array}{l}
\text { persamaan regresi kurva kalibrasi } \\
(\mathrm{ppm})
\end{array} \\
\mathrm{Fp} & =\text { Faktor pengenceran } \\
\mathrm{V} & =\text { volume total sampel }
\end{array}
$$


Rumus perhitungan persen kadar vitamin

C pada sampel :

$$
\frac{\text { Cs. Fp. V }}{\mathrm{W}} \times 100 \%
$$

Keterangan :

$\mathrm{W}=$ Bobot total sampel

\section{Hasil dan Pembahasan}

Hasil kurva kalibrasi dari larutan Vitamin C konsentrasi 100 ppm, 200 ppm,
300 ppm, 400 ppm dan 500 ppm, didapatkan nilai $\mathrm{Y}=40,53087 \mathrm{x}+$ 49,71443 dengan nilai $r=0,99982$. Berikut adalah kurva kalibrasi standar vitamin $\mathrm{C}$ (Gambar 1) Analisa sampel serbuk vitamin C (SVCM) dan (SVCP) dilakukan masingmasing sebanyak replikasi $2 \mathrm{x}$. Data konsentrasi sampel, dirangkum dalam Tabel 1.

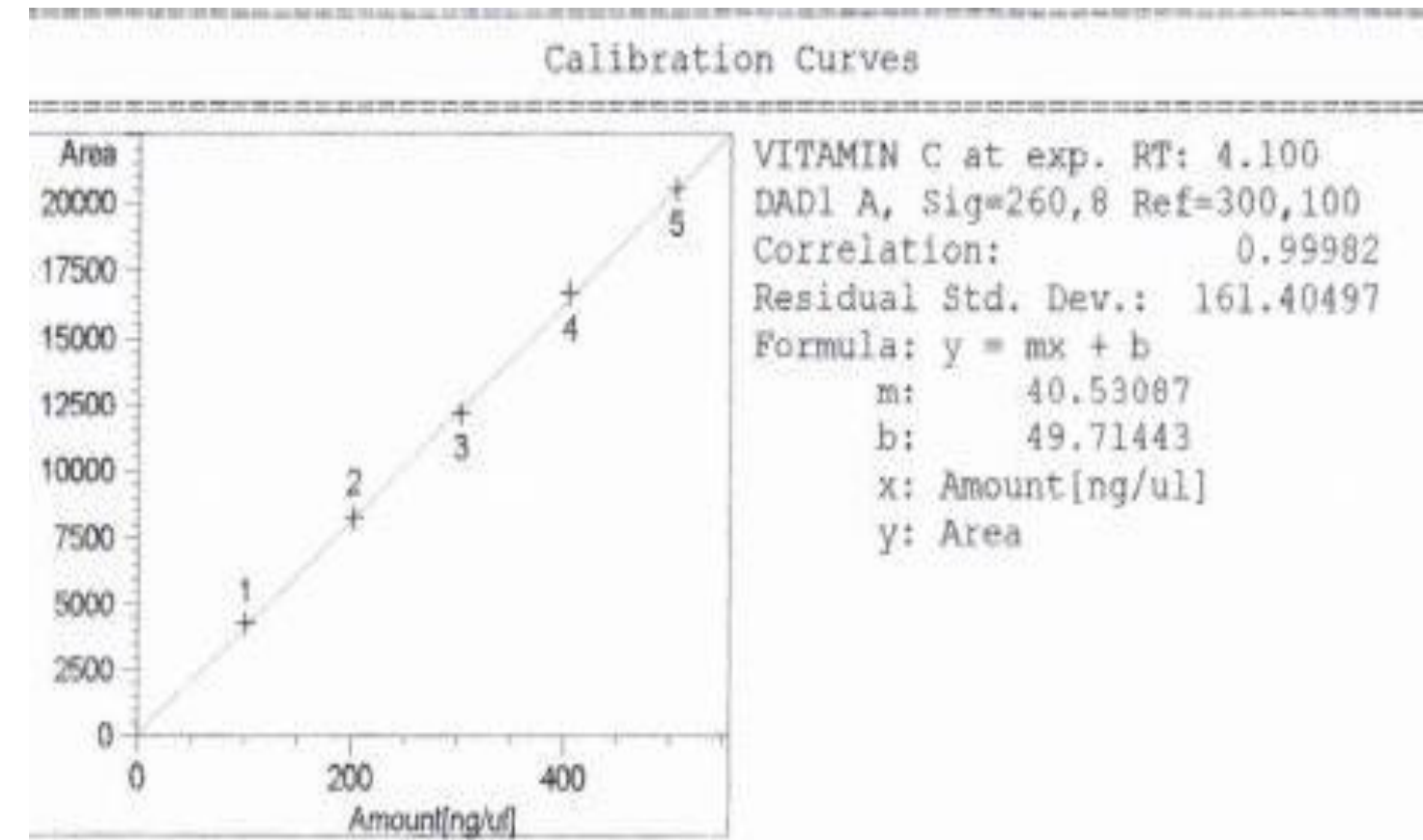

Gambar 1. Kurva Kalibrasi Standar Vitamin C

Tabel 1. Konsentrasi sampel vitamin C

\begin{tabular}{|c|c|c|c|c|c|c|c|c|c|}
\hline $\begin{array}{c}\text { Kode } \\
\text { sampel }\end{array}$ & $\begin{array}{c}\text { Area } \\
\text { Sampel }\end{array}$ & $\begin{array}{c}\text { Berat } \\
(\mathrm{mg})\end{array}$ & $\begin{array}{c}\text { Ppm } \\
\text { terukur } \\
(\text { Vit C) }\end{array}$ & $\begin{array}{l}\text { Dilusi } \\
(10 \\
\text { kali) } \\
(\mathbf{p p m})\end{array}$ & $\begin{array}{c}\text { Berat } \\
\text { dalam 50 } \\
\text { mL (Vit C } \\
\text { (mg) }\end{array}$ & $\% \mathrm{~b} / \mathrm{b}$ & $\begin{array}{c}\text { Rata- } \\
\text { rata }\end{array}$ & SD & RPD \\
\hline SVCP1 & 14738,50 & 1020,40 & 362,41 & 3.624 & 181,2014 & 17,758 & \multirow{2}{*}{17,688} & \multirow{2}{*}{0,100} & \multirow{2}{*}{$0,797 \%$} \\
\hline SVCP2 & 14631,60 & 1021,10 & 359,77 & 3.597 & 179,886 & 17,617 & & & \\
\hline $\begin{array}{c}\text { SVCM } \\
1 \\
\end{array}$ & 15607,00 & 1023,10 & 383,84 & 3.838 & 191,919 & 18,759 & \multirow{2}{*}{18,807} & \multirow[b]{2}{*}{0,069} & \multirow[b]{2}{*}{$0,509 \%$} \\
\hline $\begin{array}{c}\text { SVCM } \\
2\end{array}$ & 15684,30 & 1022,90 & 385,74 & 3.857 & 192,872 & 18,855 & & & \\
\hline
\end{tabular}

Berdasar data yang diperoleh dalam Tabel 1, diketahui bahwa kadar asam askorbat dari tablet vitamin $\mathrm{C}$ hasil penggerusan secara manual dengan menggunakan mortir-stamper adalah lebih tinggi dibandingkan dengan serbuk vitamin $\mathrm{C}$ hasil penggerusan dengan alat elektronik pulverization. Hal tersebut dikarenakan alat pulverization merupakan alat elektronik yang dapat menghasilkan panas sehingga dapat mengurai asam askorbat (Hok et al, 2007).

Pada Farmakope Indonesia Edisi IV disebutkan bahwa tablet vitamin $\mathrm{C}$ 
mengandung Asam Askorbat $\mathrm{C}_{6} \mathrm{H}_{8} \mathrm{O}_{6}$ tidak kurang dari $90 \%$ dan tidak lebih dari 110 , $0 \%$ dari kadar yang tertera pada etiket (Depkes RI, 2009)

Penelitian ini menggunakan sampel tablet vitamin $\mathrm{C}$ dengan bobot per tablet $250 \mathrm{mg}$ dan kandungan asam askorbat 50 $\mathrm{mg}$, sehingga persyaratan kandungan vitamin $\mathrm{C}$ yang memenuhi adalah $45 \mathrm{mg}$ $55 \mathrm{mg}$ per tablet vitamin $\mathrm{C}$.

Penelitian ini menggunakan sampel dengan bobot $1000 \mathrm{mg}$, yang berarti dibutuhkan 4 tablet sehingga kandungan asam askorbat sesuai dengan etiket adalah $50 \mathrm{mg} \times 4$ tablet $=200 \mathrm{mg}$.

Hasil uji penetapan kadar SVCP ratarata (hasil replikasi 2x) adalah 180,545 $\mathrm{mg}$, bila dibandingkan dengan nilai kadar yang sebenarnya adalah 180,545 mg/ 200 mb x $100 \%=90,27 \%$. Kadar SVCM ratarata adalah 192,396 mg, dibanding dengan nilai kadar sebenarnya adalah $192,396 \mathrm{mg} /$ $200 \mathrm{mg}$ x $100 \%$ dan kadar SVCM rata-rata adalah $96,20 \%$.

Dari data hasil penelitian tersebut dapat dikatakan baik vitamin $\mathrm{C}$ yang digerus manual dengan vitamin $\mathrm{C}$ yang digerus dengan alat elektronik pulverization,keduanya masih memiliki kandungan asam askorbat yang memenuhi persyaratan FI IV.

Berdasar hasil penelitian ini, dapat dikatakan bahwa pelayanan kefarmasian peracikan sediaan pulveres vitamin $\mathrm{C}$ dapat dilakukan secara lebih cepat (bila menggunakan alat pulverization) serta tidak menjadikan mutu sediaan pulveres menjadi berkurang atau berbeda dibanding dengan metode penggerusan manual.

Bila ditinjau dari segi metode penetapan kadar vitamin $\mathrm{C}$, metode yang

\section{Daftar Pustaka}

Allen, L,V., and Ansel, H,C. 2014. Pharmaceutical Dosage Forms and Drug Delivery Systems $\mathrm{Ed}^{10}$. USA: Lippincott Williams\& Wilkins. digunakan dalam penelitian ini membutuhkan sampel uji $50 \%$ lebih hemat dibanding metode spektrofotometer UV, selain itu juga membutuhkan jumlah pelarut 4x lipat lebih banyak dibanding metode HPLC (Techinamuti \& Pratiwi, 2018).

Selain itu kelebihan HPLC dalam pengukuran vitamin $\mathrm{C}$ adalah lebih akurat dibanding dengan titrasi iodometri. Metode titrasi iodometri lebih sederhana serta tidak memerlukan instrument yang lebih canggih dibanding HPLC, namun hasil yang didapat kurang akurat karena vitamin $C$ dapat dipengaruhi oleh zat lain.

Hal tersebut diatas dikarenakan, pada titrasi iodometri, larutan vitamin $\mathrm{C}$ sebagai reduktor dioksidasi oleh iodium hingga habis teroksidasi. Selanjutnya kelebihan iodium akan dapat terdekteksi oleh kelebihan amylum. Kelebihan amylum akan menjadikan sampel berwarna biru muda yang menandakan $\mathrm{pH}$ sampel berubah menjadi basa ( Wijanarko, 2002).

\section{Kesimpulan}

Teknik penggerusan tablet vitamin $\mathrm{C}$ metode manual mortir-stamper dan dengan alat blender (pulverization) tetap menghasilkan sediaan serbuk vitamin $\mathrm{C}$ dengan kandungan asam askorbat sesuai dengan persyaratan FI IV. Metode penetapan kadar vitamin $\mathrm{C}$ dengan metode HPLC terbukti akurat.

\section{Ucapan Terima Kasih}

Penulis mengucapkan terima kasih kepada Akademi Farmasi Surabaya yang telah mendanai penelitian ini melalui Dana Penelitian Internal Tahun 2019.

Bestari, N, A., Sulaiman, S, N, T \& Purnamasari, A, D. 2017. Pengaruh Pengecilan Ukuran Partikel pada Kasus Pembuatan Pulveres dari Tablet Ibuprofen Terhadap Kecepatan dan Profil Disolusi Serta Stabilitasnya. Majalah Farmaseutik, 13 (1), 45-55. 
Departemen Kesehatan Republik Indonesia. 1995. Farmakope Indonesia. Depkes-RI

Departemen Kesehatan Republik Indonesia. 2009. Farmakope Indonesia. Depkes-RI

Duerbeck, N.B., Dowling, D.D., Duerbeck, J.M., 2016. Vitamin C: Promises Not Kept. Obstet. Gynecol. Surv. 71, 187-193.

Gandjar, I, G., \& Rohman, A. 2007. Kimia Farmasi Analisis. Yogyakarta: Pustaka Pelajar.

Gunawan, S, G., Nafrialdi, R, S., \& Elysabeth. 2008. Farmakologi dan Terapi. Edisi 5. Jakarta: Departemen Farmakologi dan Terapeutik Fakultas Kedokteran UI.

Hasanah, U. 2003. Pemeriksaan Mutu Fisik dan Keseragaman Kandungan Kapsul Isoniazid 200 mg Hasil Racikan Apotek (Di Beberapa Apotek Wilayah Surabaya Utara).Skripsi. Universitas Airlangga.

Hok, T, K., Setyo, W., Irawaty, W., \& Soetaredjo. 2007. Pengaruh Suhu dan Waktu Pemanasan Terhadap Kandungan Vitamin A dan Vitamin C Pada Proses Pembuatan Pasta Tomat. Widya Teknik, 6 (2), 111-120.
Jubahar, J., Astuti, Y \& Suharti, N. 2015. Penetapan Kadar Vitamin C Dari Buah Cabe Rawit (Capsicum frutescens L.) Dengan Metode Kromatografi Cair Kinerja Tinggi (KCKT). Jurnal Farmasi Higea, 7 (2).

Lachman, L., Lieberman, H,A., and Kanig, J,L. 1989. Teori dan Praktek Farmasi Industri. UI-Press.

Martindale $\mathrm{Ed}^{36}$ 2009. The Complete Drug References. RPS Publishing.

Sumardjo, D. 2008. Pengantar Kimia: Buku Panduan Kuliah Mahasiswa Kedokteran dan Program Strata I Fakultas Bioeksakta. Semarang: EGC.

Techinamuti, N \& Pratiwi, R. 2018. Review : Metode Analisis Kadar Vitamin C. Farmaka, 16 (2), 309315.

Widyaswari, R \& Wiedyaningsih, C. 2012. Evaluasi Profil Peresapan Obat Racikan dan Ketersediaan Formula Obat Untuk Anak di Puskesmas Propinsi DIY. Majalah Farmaseutik, 8: (3)

Wijanarko \& Bambang, S. 2002. Analisis Hasil Pertanian. Malang: Universitas Brawijaya 